\title{
Um estado do conhecimento sobre trabalho colaborativo: Uma análise de artigos publicados no Brasil
}

\author{
Flávia Cristina de Macêdo Santana \\ Universidade Estadual de Feira de Santana \\ flaviacris.uefs@gmail.com
}

\section{Jonei Cerqueira Barbosa}

Universidade Federal da Bahia

jonei.cerqueira@ufba.br

\begin{abstract}
Resumo
Este artigo tem por objetivo sistematizar e analisar estudos sobre trabalho colaborativo com professores de matemática. Para tanto, foi realizada uma pesquisa do tipo estado do conhecimento sobre o tema e os artigos selecionados para compor o corpus foram publicados entre o período de 2003 a 2014. Após a seleção e leitura desses artigos, foram identificadas três categorias analíticas, a saber: conceptualizações teóricas sobre trabalho colaborativo; organização e funcionamento do grupo de trabalho colaborativo; implicações da participação (de professores de matemática) em trabalho colaborativo. Dentre os resultados, o estudo mostra a necessidade de desenvolvimento de novas pesquisas sobre trabalho colaborativo apoiados em outras lentes teóricas, que a forma de organização e funcionamento do grupo está associada ao contexto em que decorre o trabalho colaborativo e as dinâmicas desenvolvidas e que a socialização de experiências e as reflexões sobre a prática contribuem para transformações e mudanças tanto pessoais como profissionais.
\end{abstract}

Palavras-chave: Estado do Conhecimento. Trabalho colaborativo. Professores de Matemática.

\section{A State of knowledge on collaborative work with math teacher: an analysis of articles published in Brazil}

\begin{abstract}
This article aims to systematize and analyze studies on collaborative work with mathematics teachers. For this, a survey of the type state of knowledge on the topic and selected articles to compose the corpus were published between the period 2003 to 2014. After selecting and reading these articles, three analytical categories were identified, namely: the different theoretical conceptualizations of collaborative work; organization and functioning of the collaborative working group; implications of participation (math teacher) in collaborative work. Among the results, the study shows the need to develop new research on collaborative work supported by other theoretical lenses that form of organization and functioning of the group is linked to the context in which runs the collaborative work and developed dynamic and socialization experiences and reflections on the practice contribute to transformation and changes both personal and professional.
\end{abstract}

Keywords: State of Knowledge. Collaborative Work. Math Teachers. 


\section{Introdução}

As discussões sobre trabalho colaborativo começaram a se consolidar no cenário das pesquisas desenvolvidas na área de Educação Matemática, principalmente, a partir da década de 2000 (PONTE; SERRAZINA, 2003; NACARATO et al., 2003; FERREIRA; MIORIM, 2003). Desde então, é possível identificar diferentes acepções e experiências sendo socializadas, revelando a diversidade de entendimentos no campo da Educação Matemática. Como consequência, isso impõe a necessidade do desenvolvimento de metapesquisas que contemplem um olhar mais globalizante sobre a natureza dos trabalhos colaborativos na referida área. Segundo o conceito proposto por Ferreira e Miorim (2011), o trabalho colaborativo é compreendido como uma modalidade de desenvolvimento profissional ${ }^{1}$ em que os membros se engajam, a fim de atingir um objetivo comum.

Para Fiorentini (2013), o trabalho colaborativo, em termos de perfis de participação e diálogo entre diferentes contextos, pode ser problematizado, compreendido e transformado mediante a análise conjunta das comunidades acadêmica e escolar. Segundo o autor, a colaboração entre professores e pesquisadores pode contribuir para diminuir a lacuna existente entre teoria e prática, bem como promover uma aproximação entre as escolas e as universidades. Para Ferreira e Miorim (2011), essa aproximação permite que o professor da educação básica seja visto como um parceiro e colaborador de novas construções e reflexões.

Em um estudo anterior, Nacarato et al. (2003) analisaram e sistematizaram um conjunto de estudos cujo objeto de investigação eram as práticas ou grupos colaborativos na formação continuada de professores que ensinam matemática. Nessa pesquisa, os autores tomaram como foco oito teses de doutorado produzidas no Programa de Pós-Graduação em Educação - área de concentração em Educação Matemática - da Faculdade de Educação da Universidade de Campinas (FE/UNICAMP), no período de 2000 a 2003. Segundo Nacarato et al. (2003), esses estudos buscam aportes teórico-metodológicos que fundamentem tanto os processos de trabalho colaborativo quanto sua investigação.

Nessa direção, emerge a necessidade de ampliar esse balanço e agregar novas sínteses sobre essa temática. Para atingir tal propósito, buscamos sistematizar e analisar estudos sobre trabalhos colaborativos com professores de matemática, de modo que se pudesse ter um panorama das produções já realizadas em nosso país nos últimos onze anos.

\footnotetext{
${ }^{1}$ Entendemos desenvolvimento profissional consoante com os estudos de Ferreira (2006), isto é, como um processo que se dá ao longo da vida, seja pessoal ou profissional, que não possui duração nem linearidade.
} 


\section{Delineamento da investigação sobre trabalho colaborativo}

Para atingirmos o objetivo proposto, adotamos o estado do conhecimento como modalidade de pesquisa, o qual, segundo Soares e Maciel (2000), caracteriza-se como um levantamento e uma avaliação da produção acadêmica e científica sobre o tema. Trata-se de uma pesquisa bibliográfica, realizada de modo não exaustivo, que nos possibilita analisar as produções acadêmicas e científicas sobre o tema de uma determinada área de conhecimento.

Para a realização desse estudo, definimos como corpus os anais de um evento e quatro periódicos da área de Educação Matemática por considerá-los fontes reconhecidas nesse campo de pesquisa. Selecionamos os artigos dos anais publicados em um dos grupos de trabalho (GT) que compõem o Seminário Internacional de Pesquisa em Educação Matemática (SIPEM), evento organizado pela Sociedade Brasileira de Educação Matemática (SBEM) - no caso, o GT 7 Formação de professores que ensinam matemática - nas edições do SIPEM de 2003, 2006, 2009 e 2012. Quanto aos periódicos, escolhemos os seguintes: Boletim de Educação Matemática (Bolema), Educação Matemática Pesquisa, Boletim do Grupo de Estudos e Pesquisas em Educação Matemática (GEPEM), e Zetetiké. Inicialmente, tínhamos escolhido um período de dez anos, a fim de capturar as tendências emergentes no tópico investigado, mas para incluir a edição de SIPEM de 2003, reformulamos o intervalo do levantamento bibliográfico para abranger os anos de 2003 a 2014.

A partir dessas escolhas, fizemos o levantamento de todos os artigos publicados. Após a leitura inicial dos títulos, palavras-chave e resumos, os artigos foram selecionados pela identificação do tema. Utilizamos como critério para a seleção final do corpus as publicações que focalizam trabalhos colaborativos com a participação de professores de matemática. Nessa etapa, foram selecionados dezenove trabalhos que se enquadraram na temática, sendo dez nos periódicos mencionados e nove nos anais do SIPEM. O Quadro 1, a seguir, apresenta o número de trabalhos publicados nos anais do SIPEM e o número de artigos presentes nos periódicos focalizados por este estudo.

Quadro 1 - Trabalhos publicados nos anais do SIPEM e nos periódicos selecionados

\begin{tabular}{|l|l|c|}
\hline ANAIS E PERIÓDICOS SELECIONADOS & \multicolumn{1}{|c|}{ ARTIGOS } & QUANTIDADE \\
\hline \multirow{5}{*}{ SIPEM } & Nacarato, et al.(2003). & \\
& Ferreira e Miorim (2003) & \\
& Lopes (2003) & \\
& Ferreira (2006) & \\
& Lopes (2006) & \\
& Gama e Fiorentini (2009a) & \\
& Nacarato e Grando (2009) & \\
& Pietropaolo et al. (2009) & \\
\hline
\end{tabular}




\begin{tabular}{|c|c|c|}
\hline & Prado e Lobo da Costa (2012) & \\
\hline BOLEMA & $\begin{array}{l}\text { Costa e Fiorentini (2007) } \\
\text { Miskulin, et al. (2011) } \\
\text { Ribeiro (2009) }\end{array}$ & 03 \\
\hline ZETETIKÉ & $\begin{array}{l}\text { Ponte e Serrazina (2003) } \\
\text { Traldi Júnior e Pires (2009) } \\
\text { Marquesin e Nacarato (2011) }\end{array}$ & 03 \\
\hline BOLETIM GEPEM & Costa (2008) & 01 \\
\hline EDUCAÇÃO MATEMÁTICA PESQUISA & $\begin{array}{l}\text { Gama e Fiorentini (2009b) } \\
\text { Costa e Lins (2010) } \\
\text { Fernandes, Carvalho e Carvalho (2010) }\end{array}$ & 03 \\
\hline TOTAL DE ARTIGOS ANALISADOS & & 19 \\
\hline
\end{tabular}

Fonte: Elaborado pelos autores

Organizamos também os resultados, compondo a sistematização das sínteses e identificando as tendências do tema abordado; por fim, a partir de uma análise transversal, buscamos identificar convergências ou divergências nos estudos analisados, tecendo algumas inferências e compreensões. Em seguida, apresentaremos um estado do conhecimento por meio das categorias definidas após a análise do corpus.

\section{Categorias de análise}

Identificamos três categorias analíticas, a saber: conceptualizações teóricas sobre trabalho colaborativo; organização e funcionamento do trabalho colaborativo; implicações da participação em trabalho colaborativo. Na primeira categoria, apresentamos os pressupostos teóricos adotados nos estudos sobre trabalho colaborativo; na segunda, tentamos verificar como o trabalho é organizado e qual é a dinâmica em funcionamento nos grupos; por fim, na terceira, buscamos identificar quais as implicações da participação, principalmente de professores de matemática, em grupos que desenvolvem esse tipo de trabalho. A seguir, apresentaremos cada uma dessas categorias e, na próxima seção, faremos a análise e discussão dos resultados.

\section{Conceptualizações teóricas sobre trabalho colaborativo}

Comecemos pela diferenciação possível entre trabalho cooperativo e colaborativo. Ponte e Serrazina (2003), Ferreira e Miorim (2003), Ferreira (2006) e Traldi Júnior e Pires (2009) demarcam essas diferenças e partem do pressuposto de que o trabalho desenvolvido por um grupo não nasce colaborativo: ele torna-se colaborativo à medida que o trabalho se desenvolve e as relações são estabelecidas. Na colaboração, os diversos participantes trabalham em conjunto, 
negociam e tomam decisões em grupo, dialogando constantemente em uma base de relativa igualdade, em que a aprendizagem pode ser acessível a todos. Na cooperação, as relações podem ser desiguais e até hierárquicas, e os objetivos, difusos e totalmente subordinados às metas individuais de apenas alguns participantes.

Na análise do corpus, verificamos que Ferreira e Miorim (2003), Lopes (2003, 2006) e Ferreira (2006) compreendem que o trabalho colaborativo tem por base as características do grupo colaborativo, expressas da seguinte maneira: a participação é voluntária e todos os envolvidos desejam crescer profissionalmente; a confiança e o respeito mútuo fundamentam todo o trabalho; os participantes trabalham juntos (co-laboram) por um objetivo comum, construindo e compartilhando significados acerca do que estão fazendo e do que isso significa para suas vidas e para sua prática; os participantes sentem-se à vontade para se expressar livremente e estão dispostos a ouvir críticas e a mudar; não existe uma verdade ou orientação única para as atividades. Segundo as autoras, cada participante pode ter diferentes interesses e pontos de vista, revelando distintas contribuições, ou seja, diversos níveis de participação. Além disso, o trabalho desenvolvido é reconhecidamente colaborativo ao longo do tempo, a partir do momento em que as relações alcançam as características apontadas.

Ferreira e Miorim (2003), Ferreira (2006), Gama e Fiorentini (2009a, 2009b) e Miskulin et al. (2011) compreendem o trabalho colaborativo em um sentido bem próximo ao da ideia de comunidade de prática, fazendo referência ao trabalho de Etienne Wenger. Uma comunidade de prática, como posto pelos autores, possibilita que os membros negociem objetivos, tarefas e estejam comprometidos com um mesmo tema. Os autores ainda argumentam que nessas comunidades, os sujeitos interagem (empreendimentos articulados) e comprometem-se com atividades conjuntas (engajamento mútuo), construindo uma relação de confiança, o que não significa que, no grupo, haja homogeneidade de ideias e ações, mas que estas devem ser partilhadas (repertório compartilhado) e negociadas. Enquanto grupo colaborativo, é visto como uma organização social que tem como base a voluntariedade, o respeito mútuo, a confiança, o comprometimento, a partilha de ideias e de experiência, como posto por Lopes (2003, 2006), Marquesin e Nacarato (2011).

A diferenciação entre trabalho cooperativo e colaborativo também é sustentada por outros autores, como Costa e Fiorentini (2007) e Costa (2008), Gama e Fiorentini (2009a, 2009b). Os artigos de Ponte e Serrazina (2003), Costa e Fiorentini (2007) e Costa (2008) destacam que a transição do trabalho cooperativo para o colaborativo começa a se evidenciar à medida que os professores passam a compartilhar suas atividades de sala de aula, trazendo episódios que desencadeiam reflexões conjuntas e apoio mútuo para as situações de dificuldade ou desafio de cada um. Nesses artigos, as temáticas relacionadas com a cultura e o trabalho docente estão alicerçadas 
na tipologia de culturas profissionais apresentada por Andy Hargreaves, que aborda o tema colaboração a partir da distinção entre formas de cultura docente.

Lopes $(2003 ; 2006)$ compreende o trabalho colaborativo como uma modalidade de desenvolvimento profissional que gera uma interdependência entre as componentes do grupo. Já Nacarato e Grando (2009), em uma perspectiva sociocultural, veem esse tipo de trabalho como um ambiente de aprendizagem ${ }^{2}$ em que predomina o diálogo, segundo a concepção freireana, ou seja, como fenômeno humano, como encontro entre os homens, em uma relação de respeito e confiança mútua, como emancipação e liberdade para aprender.

Identificamos, entre as pesquisas analisadas, que existe uma limitação em termos de lentes teóricas sobre o tema desta investigação. Há uma tendência em se demarcar uma diferenciação entre os termos cooperativo e colaborativo, fruto de uma influência portuguesa, como podemos observar nos trabalhos de Ponte e Serrazina (2003). Além disso, destacamos um direcionamento para a compreensão do conceito de trabalho colaborativo tendo como base a Teoria Social da Aprendizagem de Etienne Wenger. Essa categoria de análise nos mostra a necessidade de desenvolvimento de novos estudos sobre trabalho colaborativo apoiados em outras lentes teóricas que nos permita analisar as relações pedagógicas e as formas de comunicação entre os diferentes sujeitos.

\section{Organização e funcionamento do grupo de trabalho colaborativo}

Inicialmente, identificamos, no corpus selecionado, o perfil dos membros dos grupos de trabalho colaborativo. As pesquisas de Ferreira e Miorim (2003), Ferreira (2006), Lopes (2003; 2006) e Nacarato e Grando (2009) mostram que participam desses grupos professores de diferentes níveis de ensino, desde os que ministram aulas na educação infantil (os denominados "polivalentes do ensino fundamental I"), como os do ensino fundamental II e do ensino médio, coordenadores, professores universitários, estudantes de graduação e de pós-graduação. Ferreira (2003) ressalta que fatores como tempo, disponibilidade, disposição, igualdade de papéis, metas e liderança compartilhada, entre outros, mostram-se como elementos de fundamental importância no processo de constituição do grupo.

Os artigos analisados mostram as diferentes formas de organização dos grupos de trabalho colaborativo. Nessa seleção de artigos, constata-se a existência de três vertentes: uma vertente em que os grupos são formados a partir de uma proposta externa, na sua maioria, vinculados a projetos de pesquisa e de extensão; outra em que os grupos são constituídos por professores da universidade

\footnotetext{
${ }^{2}$ Ambiente de aprendizagem são as condições nas quais os alunos são estimulados a desenvolver determinadas atividades (SKOVSMOSE, 2008).
} 
para o estudo de temas específicos na universidade; e, por fim, outra vertente em que os grupos são constituídos a partir das necessidades de grupos de professores da educação básica em que as reuniões se realizam no contexto escolar.

$\mathrm{Na}$ primeira vertente, encontramos os trabalhos de Ferreira e Miorim (2003), Ferreira (2006), Lopes (2003; 2006), Nacarato e Grando (2009), Gama e Fiorentini (2009a; 2009b) e Ribeiro (2009), vinculados a projetos institucionais de pesquisas. Pietropaolo et al. (2009) relatam que o trabalho desenvolvido esteve vinculado ao programa Observatório de Educação (OBEDUC), da Coordenação de Aperfeiçoamento de Pessoal de Nível Superior (CAPES) e do Instituto Nacional de Estudos e Pesquisas Educacionais Anísio Teixeira (INEP). Na mesma direção, Ribeiro (2009) tece considerações sobre um grupo constituído no âmbito de um Programa de Formação Continuada em Matemática para professores do $1^{\circ}$ e $2^{\circ}$ ciclos do ensino básico (PFCM). Na segunda vertente, há o trabalho de Traldi Júnior e Pires (2009), que apresenta o grupo formado por sete professores que lecionam a disciplina de Cálculo Diferencial e Integral, em uma instituição particular do Estado de São Paulo. Na terceira vertente, o artigo de Prado e Lobo da Costa (2012) contempla a necessidade dos professores da educação básica de estudar uma proposta curricular em implementação na escola.

No que se refere à dinâmica de trabalho, verificamos algumas semelhanças entre grupos colaborativos. Para Costa e Fiorentini (2007, 2008), Ferreira e Miorim (2003) e Ferreira (2006), essas equipes têm em comum uma prática coletiva centrada no estudo, na reflexão e na investigação sobre/da prática docente em matemática nas escolas. Em termos de relações pedagógicas, observamos que os trabalhos de Ponte e Serrazina (2002), Ferreira (2006), Prado e Lobo da Costa (2012) constatam que, em qualquer relação, pode haver tensões e conflitos, desequilíbrio perante a distribuição de algumas funções, apresentação de sentimentos de revolta e, em determinados momentos, certos membros podem querer impor sua vontade.

Os artigos de Ponte e Serrazina (2003), Lopes (2003, 2006), Costa e Fiorentini (2007), Costa (2008), Gama e Fiorentini (2009a, 2009b) e Nacarato e Grando (2009) mostram que o apoio e o respeito mútuos são essenciais, e que a existência de um líder para a condução das atividades torna-se um diferencial para o encaminhamento dos trabalhos. Segundo esses autores, esse fato não descaracteriza o aspecto colaborativo, a corresponsabilidade nas ações e a gestão compartilhada, mas revelam que é a partir de um contato inicial com o grupo e da identificação das demandas que novas ações são agendadas.

Quanto ao tempo de contato entre os membros, observamos que geralmente as reuniões são quinzenais, com duração mínima de duas horas, como revela o trabalho de Lopes (2006) e Ferreira (2006). Constatamos que, quando os trabalhos estão vinculados a projetos institucionais, como por 
exemplo, o trabalho de Pietropaolo et al (2009), cujo tempo de vigência é de dois a quatro anos, há uma forte tendência à continuidade, independentemente do financiamento, o que marca de modo claro o caráter voluntário dos integrantes. Por outro lado, quando os grupos de trabalhos colaborativos são formados a fim de atender a particularidades de determinadas pesquisas, existe uma tendência de redução de seu tempo de vigência. Na maioria das vezes, o contato entre os membros tem a durabilidade de um ano e o número de encontros é menor, como mostra o estudo de Traldi Júnior e Pires (2009) e Lopes (2003, 2006).

Essa categoria de análise nos permite inferir que, o trabalho colaborativo se constitui em uma prática que pode envolver diferentes sujeitos e que a forma de organização e funcionamento do grupo está associada ao contexto em que decorre o trabalho colaborativo e as dinâmicas desenvolvidas.

\section{Implicações da participação em um trabalho colaborativo}

Os estudos de Costa e Fiorentini (2007), Costa (2008), Gama e Fiorentini (2009a, 2009b), Marquesini e Nacarato (2011), Lopes (2003, 2006), Pietropaolo et al (2009) e Prado e Lobo da Costa (2012) sugerem que o trabalho colaborativo pode desencadear e ampliar a capacidade de reflexão dos profissionais vinculados a projetos comuns e diminuir a lacuna existente entre a escola e a universidade. Além disso, como se pode observar no corpus analisado, os autores colocam em pauta questões relacionadas com conceitos matemáticos e estratégias utilizadas para uma gestão diferenciada em sala de aula.

Trabalhos dessa natureza podem envolver professores que se predisponham a participar em diferentes momentos da vida profissional e em qualquer nível de ensino. Gama e Fiorentini (2009a, 2009b), por exemplo, tomaram como foco o trabalho colaborativo do qual participavam professores iniciantes de três grupos colaborativos (GdS, GEM e GCEEM) ${ }^{3}$. Os autores afirmam que esses professores encontram nesse tipo de trabalho um contexto favorável ao desenvolvimento profissional, pois consideram o apoio mútuo um diferencial, ajudando-os a: inserir-se criticamente na comunidade de professores da escola; desenvolver uma postura reflexiva sobre a própria prática; realizar uma prática pedagógica mais interativa e exploratório-investigativa, que favorece a produção e a negociação de significados; e a adotar uma prática de trabalho coletivo em lugar de uma prática individualista.

\footnotetext{
${ }^{3}$ Grupo de Sábado (GdS), sediado na Faculdade de Educação da Universidade Estadual de Campinas; Grupo de Educação Matemática (GEM), do Departamento de Metodologia de Ensino-Universidade Federal de São Carlos; Grupo Colaborativo de Estudos em Educação Matemática (GCEEM), da Diretoria Regional de Americana (SP).
} 
Em outro estudo, Gama e Fiorentini (2009b) destacam que os professores iniciantes, ao se inserirem em trabalhos colaborativos, inicialmente, tendem a participações periféricas, porém são instigados a refletir sobre situações desafiadoras e complexas das práticas pedagógicas e docentes dos participantes (GAMA e FIORENTINI, 2009b). Aos poucos, os iniciantes adquirem confiança e passam a compartilhar com o grupo suas próprias experiências, suas angústias, suas dificuldades e seus aprendizados obtidos na prática. Cabe ressaltar que as ações realizadas nos grupos não promovem apenas o desenvolvimento profissional do professor, mas as experiências vivenciadas pela equipe adquirem características formativas para todos os envolvidos. Em ambos estudos, portanto, os autores afirmam que a participação dos professores iniciantes em trabalhos colaborativos propicia reflexões sobre a prática, maior interlocução com seus pares e com a comunidade e o desenvolvimento do trabalho coletivo, em lugar de um trabalho isolado ou autocentrado.

Ampliamos nosso foco e inserimos, nesta seção, os artigos que abordam estudos referentes ao trabalho colaborativo com professores experientes, destacando as implicações dessa prática para o ensino e a aprendizagem de conteúdos de matemática. Fernandes, Carvalho e Carvalho (2010), ao estudarem a influência do trabalho colaborativo no desenvolvimento do conhecimento didático dos professores em combinatória, mostram que há uma mudança nas concepções e perspectivas desses professores. Eles identificaram que as discussões evoluíram em torno do conteúdo, centrando-se no conceito de combinatória e, posteriormente, na reflexão sobre o currículo, a prática e a intervenção envolvendo os alunos.

De forma similar, Marquesini e Nacarato (2011) e Prado e Lobo da Costa (2012) apresentam o movimento entre o saber dos conteúdos em geometria e o saber da prática, produzido por professoras dos anos iniciais do ensino fundamental, participantes de um grupo colaborativo. Nesses trabalhos, as opções, as concepções e experiências em relação ao ensino e à aprendizagem de matemática e de geometria também são claramente reveladas. Marquesini e Nacarato (2011) mostram que o trabalho desenvolvido colaborativamente foi primordial para que as transformações ocorressem e houvesse uma (re)significação dos saberes profissionais em geometria. Ressaltam também que, por inúmeras vezes, algumas intervenções foram necessárias no sentido de incentivar o grupo, enfatizando que as aprendizagens e as mudanças aconteceriam a partir das incertezas e das novas conquistas durante o processo de realização da proposta de trabalho.

Ferreira e Miorim (2003) e Ferreira (2006), ao desenvolverem um trabalho colaborativo com professoras de matemática, elegeram como foco de investigação as frações. As autoras revelam que essa escolha desencadeou uma participação mais ativa por parte das professoras, pois havia a necessidade de discutir e estruturar cada passo, dos objetivos às atividades, das classes que estariam 
envolvidas com a análise. Por sua vez, Ribeiro (2009) apresenta um caso específico para a multiplicação com números decimais e sinaliza a possibilidade de socialização de diferentes abordagens para o ensino desse conteúdo por meio do trabalho colaborativo.

Constatamos, diante do que foi exposto, que Ferreira e Miorim (2003), Ferreira (2006), Nacarato e Grando (2009), Ribeiro (2009), Fernandes, Carvalho e Carvalho (2010), Marquesin e Nacarato (2011) corroboram Lopes (2003, 2006) quando sugerem a escolha de uma temática específica como um alicerce para o desenvolvimento do trabalho colaborativo. Os autores apontam para a potencialidade do desenvolvimento profissional de um grupo quando este toma um conteúdo matemático em especial como objeto de investigação.

Costa e Fiorentini (2007) e Costa (2008) não focalizam apenas a questão do conteúdo, mas também indicam reflexões sobre a forma como o trabalho é desenvolvido. Os autores argumentam que o desenvolvimento de um trabalho colaborativo pode promover indícios de mudança na cultura docente com o auxílio das tecnologias de informação e comunicação (TIC) na prática pedagógica. Ressaltam, ainda, que, em relação ao conteúdo, as professoras participantes passaram a refletir sobre as limitações e lacunas apresentadas nos livros didáticos e nas diretrizes curriculares, bem como a refletir sobre a organização dos conteúdos de forma linear e por série. Além disso, começaram a perceber a falsa correlação dos conteúdos com a idade e a estabelecer uma maior inter-relação dos conteúdos com as novas tecnologias.

Na mesma direção, Costa e Lins (2010) e Miskulin et al. (2011) reafirmam a existência de um processo formativo, mas também sinalizam a possibilidade de trabalhos colaborativos pela virtualidade da comunidade gerada pelas TIC. Miskulin et al. (2011), por exemplo, destacam a interação que propicia suporte à troca de informação/comunicação: alunos/alunos, alunos/professores e alunos/ professores/ambientes online, mantendo viva uma conexão; e a colaboração, que apoia o desenvolvimento de projetos colaborativos, levando a uma reflexão compartilhada, a uma aprendizagem social, e reduzindo o isolamento entre os diferentes sujeitos. $\mathrm{O}$ que nos leva a inferir a existência de espaços tanto presenciais quanto virtuais para a legitimação do trabalho colaborativo.

Essa categoria sugere o que acontece quando professores de matemática socializam experiências e refletem sobre a prática no âmbito do trabalho colaborativo, contribuindo para transformações e mudanças tanto pessoais como profissionais. Observamos, no corpus selecionado, que o trabalho colaborativo favorece o desenvolvimento de um trabalho conjunto, promove discussões e reflexões sobre conteúdos de matemática relacionados a diferentes eixos, como números e operações, espaço e forma, grandezas e medidas, tratamento da informação, e viabiliza um debate sobre questões relacionadas com a prática, promovendo o aprimoramento profissional. 


\section{Discussão dos resultados}

Nesta seção, mostraremos uma discussão sobre as evidências identificadas na apresentação dos resultados dos estudos que compõem o corpus de análise do estado do conhecimento sobre trabalho colaborativo. Para atingirmos o objetivo desta pesquisa, identificamos, na seção anterior, as seguintes categorias: conceptualizações teóricas sobre trabalho colaborativo; organização e funcionamento do grupo de trabalho colaborativo; e implicações da participação (de professores de matemática) em trabalho colaborativo.

O resultado da análise dos estudos sobre o tema em questão permitiu compreender a gênese, a constituição e a repercussão de trabalhos dessa natureza, traduzidos em dois eixos interrelacionados: indícios de normas acordadas no trabalho colaborativo e indícios da legitimidade do trabalho colaborativo na interlocução entre os pares. Os eixos enunciados serão aqui retomados separadamente para efeitos de análise; contudo, compreendemos que eles ocorrem de forma imbricada, em que um não existe sem a presença do outro.

Indícios de normas acordadas no trabalho colaborativo estão relacionados com as regras subjacentes a essa prática. $\mathrm{Na}$ análise desenvolvida, apreendemos que o trabalho colaborativo é fruto das atividades do grupo, entendido como organização social e regido por princípios interrelacionados, como por exemplo, espontaneidade, voluntariedade, responsabilidade e interatividade. Apesar de os grupos que desenvolvem um trabalho colaborativo terem por base diferentes pressupostos epistemológicos e metodológicos, eles pautam-se em ações, como sinaliza Fiorentini (2013). Segundo o autor, "em um trabalho colaborativo os membros estudam, problematizam, refletem, investigam e escrevem sobre a complexidade de ensinar e aprender matemática nas escolas e negociam as práticas curriculares desejáveis e possíveis para cada realidade" (FIORENTINI, 2013, p. 70). Dessa forma, faz-se necessário levar em conta o que o grupo faz, as relações que são construídas, as atividades desenvolvidas e os saberes partilhados e construídos. Para Cyrino (2009), a oportunidade de refletir/discutir sobre a prática pode promover mudanças e, nesse sentido, as discussões culminam com a escolha de novos temas e com a seleção de artigos geradores de novos debates. Essas discussões, por sua vez, fundamentam e dão subsídios à elaboração de tarefas a serem aplicadas em sala de aula.

Indícios da legitimidade do trabalho colaborativo na interlocução entre os pares referem-se às relações estabelecidas e à forma como os participantes veem o trabalho desenvolvido pelo grupo. Os estudos analisados preconizam que, em trabalhos desenvolvidos de modo colaborativo, é necessário priorizar relações de confiança, respeito e responsabilidade. Podemos afirmar que, na dinâmica de trabalho, não há apenas alguém que ensina e um outro que aprende, mas sim, que há 'aprendizagem mútua' e 'ensino mútuo'. 
Em uma conferência, Fiorentini (2013) destacou que os formadores que trabalham na universidade também aprendem ao participar de grupos de trabalhos colaborativos. Esses formadores, ao investigarem o desenvolvimento dos professores em contextos de práticas colaborativas e investigativas, têm a oportunidade de refletir sobre suas próprias ações e passam a fazer novas leituras sobre a formação docente e o modo como podem iniciar os futuros professores nas práticas investigativas com outros docentes. Fiorentini (2010a) afirma que os formadores e os professores da escola, investigando juntos, constroem novos modos de ensinar e aprender, engajando os alunos da licenciatura e da escola como parceiros e corresponsáveis pela construção de novas práticas de aprendizagem.

Na mesma direção, Santana e Bortoloti (2014) revelam que os formadores universitários podem mudar suas ideias quando dialogam com diferentes sujeitos. No primeiro estudo, o autor enfatiza que aqueles profissionais percebem novos sentidos para a própria prática quando participam de um trabalho colaborativo. No segundo, as autoras ressaltam a possibilidade de trabalhar em parceria e ver, no diálogo com os professores da educação básica, a oportunidade de refletir sobre experiências de sala de aula. Os resultados apontam que a participação de formadores universitários na constituição de grupos de trabalho colaborativo pode incentivar professores de matemática, futuros professores e estudantes da pós-graduação a desenvolverem novos estudos e produções, possibilitar crescimento pessoal e profissional e propiciar reflexões e mudanças.

\section{Algumas considerações}

No presente artigo, sistematizamos e analisamos estudos sobre trabalho colaborativo envolvendo professores de matemática e, desse modo, identificamos a gênese, a constituição, a organização e o funcionamento dos grupos de trabalho colaborativo e as implicações da participação em grupos como esses. Além disso, ao desenvolvermos uma análise transversal, identificamos aspectos que nos permitiram inferir a prática adotada pelos grupos em diferentes contextos, seja decidindo o conteúdo a ser estudado, seja verificando, elaborando propostas pensadas e gestadas pelo grupo, bem como implementando propostas em ambientes virtuais.

Os resultados apontam que o trabalho colaborativo tem sido indicado como uma prática promissora, capaz de promover uma aproximação entre diferentes contextos, diminuir a lacuna existente entre escola e universidade e permitir que o professor socialize suas experiências. Essa prática possibilita o estabelecimento de diferentes relações, seja entre professores e professores, entre professores e acadêmicos ou entre acadêmicos e acadêmicos. Essa diversidade de relações pode favorecer o diálogo e a articulação de diferentes saberes e legitimar novas ações. 
Diante disso, este estudo pode trazer implicações para a formação inicial e continuada de professores, contribuindo para o debate na área de Educação Matemática, no que tange às discussões sobre o trabalho colaborativo envolvendo professores de matemática. Destacamos também a ausência de pesquisas que mostram como os professores, pós-graduandos e graduandos dessa área do saber se reconhecem como membros de uma organização social, em diferentes perspectivas, e as possibilidades de investigação do paralelo entre identidade e prática, que estão imbricadas.

Por fim, de acordo com os procedimentos adotados para a realização deste estado do conhecimento, reconhecemos a possibilidade de termos deixado de fora algum estudo que atendesse aos critérios da pesquisa. Consideramos, contudo, que os trabalhos analisados foram suficientes para revelar lacunas e contribuir para novas discussões na área de Educação Matemática.

\section{Agradecimentos}

Aos amigos do Grupo de Ensino de Ciências e Matemática (ENCIMA), em especial à Ana Virgínia de Almeida Luna, Jamile Vilas Boas, Jaqueline P. Grilo, Maria Rachel P. P. Queiroz e Roberta Bortoloti pelas contribuições.

\section{Referências}

COSTA, Gilvan Luiz Machado; FIORENTINI, Dario. Mudança da cultura docente em um contexto de trabalho colaborativo de introdução das tecnologias de informação e comunicação na prática escolar. Bolema, Rio Claro (SP), v. 20, n. 27, p. 1-19, jul., 2007.

COSTA, Gilvan Luiz Machado. Trabalho colaborativo mediado pelas tecnologias de informação e comunicação na formação de professor de matemática: indícios de mudança da cultura docente. Boletim GEPEM, n. 52, p. 69-84, jan./jun. 2008.

COSTA, Marília L. C. da; LINS, Abigail Fregni. Trabalho colaborativo e utilização das tecnologias da informação e comunicação na formação do professor de Matemática. Educação Matemática. Pesquisa, São Paulo, v.12, n. 3, p. 452-470, 2010.

CYRINO, Márcia. C. C. T. Comunidades de prática de professores como espaço de investigação sobre a formação de professores de matemática. In: BATISTA, I. L. (Org.). Pós-graduação em ensino de ciências e educação matemática: um perfil de pesquisas. Londrina: EDUEL, 2009. p. 95-110.

FERNANDES; José António; CARVALHO, Bárbara do Alvar de; CARVALHO, Carolina Fernandes de. O Trabalho Colaborativo Como Meio de Desenvolver o Conhecimento Didáctico de Duas Professoras em Combinatória. Educação Matemática Pesquisa, São Paulo, v.12, n.1, p.4374, 2010.

FERREIRA, Ana Cristina; MIORIM, Maria Ângela. O grupo de trabalho colaborativo em educação matemática: análise de um processo vivido. In: SEMINÁRIO INTERNACIONAL DE PESQUISA 
EM EDUCAÇÃO MATEMÁTICA, 2, 2003, Santos (SP). Anais... Santos: SBEM, 2003. 1 CDROM.

FERREIRA, Ana Cristina. Desenvolvimento profissional de professoras de matemática em um grupo colaborativo: uma visita aos bastidores metodológicos da pesquisa. In: SEMINÁRIO INTERNACIONAL DE PESQUISA EM EDUCAÇÃO MATEMÁTICA, 3, 2006. Águas de Lindóia. Anais... Águas de Lindóia: SBEM, 2006. 1 CD-ROM.

FERREIRA, A. C.; MIORIM, M. A. Collaborative work and the professional development of mathematics teachers: analysis of a Brazilian experience. In: BEDNARZ, N; FIORENTINI, D.; HUANG, R. (Org.). International approaches to professional development of mathematics teachers. Ottawa: University of Ottawa Press, 2011.

FIORENTINI, D. A Investigação em Educação Matemática desde a perspectiva acadêmica e profissional: desafios e possibilidades de aproximação. Cuadernos de Investigación y Formación en Educación Matemática. Costa Rica, ano 8, n. 11, pp 61-82, 2013.

GAMA, Renata Prenstteter; FIORENTINI, D. Formação continuada em grupos colaborativos: professores de matemática iniciantes e as aprendizagens da prática profissional. Educação Matemática Pesquisa, São Paulo, v.11, n.3, p.441-461, 2009a.

. Desenvolvimento profissional de professores de matemática em início de carreira que participam de grupos colaborativos. In: SEMINÁRIO INTERNACIONAL DE PESQUISA EM EDUCAÇÃO MATEMÁTICA, 4, 2009. Brasília (DF). Anais... Brasília: SBEM, 2009b. 1 CDROM.

LOPES, Celi Aparecida Espasandin. Conhecimento profissional e grupo colaborativo: uma pesquisa com educadoras matemáticas na infância. In: SEMINÁRIO INTERNACIONAL DE PESQUISA EM EDUCAÇÃO MATEMÁTICA, 2, 2003, Santos (SP). Anais... Santos: SBEM, 2003. 1 CDROM.

. O desenvolvimento profissional da professora Adriana. In: SEMINÁRIO INTERNACIONAL DE PESQUISA EM EDUCAÇÃO MATEMÁTICA, 3, 2006. Águas de Lindóia (MG). Anais... Águas de Lindóia: SBEM, 2006. 1 CD-ROM.

MARQUESIN, D. F. B e NACARATO, A. M.. A prática do saber e o saber da prática em geometria: análise do movimento vivido por um grupo de professores dos anos iniciais do Ensino Fundamental. Zetetiké - Cempem /FE/ Unicamp, Campinas, v. 19, n. 35, p. 103-137, jan./jun. 2011.

MISKULIN, Rosana Giaretta Sguerra; PENTEADO, Miriam Godoy; RICHIT, Andriceli; MARIANO, Carla Regina. A Prática do Professor que Ensina Matemática e a Colaboração: uma reflexão a partir de processos formativos virtuais. Bolema, Rio Claro (SP), v. 25, n. 41, p. 173-186, dez. 2011.

NACARATO, Adair; et al. Um estudo sobre pesquisas de grupos colaborativos na formação de professores de matemática. In: SEMINÁRIO INTERNACIONAL DE PESQUISA EM EDUCAÇÃO MATEMÁTICA, 2, 2003, Santos (SP). Anais... Santos: SBEM, 2003. 1 CD-ROM.

NACARATO, Adair Mendes; GRANDO, Regina Célia. Análise compartilhada de aulas: processo formativo $n a$, $d a$ e sobre a docência. In: SEMINÁRIO INTERNACIONAL DE PESQUISA EM EDUCAÇÃO MATEMÁTICA, 4, 2009, Brasília (DF). Anais... Brasília: SBEM, 2009. 1 CD-ROM.

PIETROPAOLO, Ruy César. Análise da constituição de um grupo de pesquisa sobre formação de professores de matemática. In: SEMINÁRIO INTERNACIONAL DE PESQUISA EM EDUCAÇÃO MATEMÁTICA, 4, 2009, Brasília (DF). Anais... Brasília: SBEM, 2009. 1 CDROM. 
PONTE, João Pedro; SERRAZINA, Lurdes. Professores e formadores investigam a sua própria prática: o papel da colaboração. Zetetiké - Cempem /FE/ Unicamp, Campinas, v. 11, n. 20, p. 9 55, jul./dez. 2003.

PRADO, Maria Elisabette Brisola Brito; LOBO DA COSTA, Nielce Meneguelo. Grupo de estudos e o professor de matemática: revendo a prática no contexto escolar. In: SEMINÁRIO

INTERNACIONAL DE PESQUISA EM EDUCAÇÃO MATEMÁTICA, 5, 2012, Petrópolis (RJ). Anais... Petrópolis: SBEM, 2012. 1 CD-ROM.

RIBEIRO, Carlos Miguel. Conhecimento Matemático para Ensinar: uma experiência de formação de professores no caso da multiplicação de decimais. Bolema, Rio Claro (SP), v. 22, n. 34, p. 1-26, dez, 2009.

SANTANA, Flávia C. de M.; Roberta d'Angela M. BORTOLOTI. O trabalho colaborativo na perspectiva de duas pós-graduandas de educação e de educação matemática. In: FÓRUM NACIONAL DE LICENCIATURAS EM MATEMÁTICA, 5, 2014, Londrina (PR). Anais... Londrina: SBEM, 2014.

SOARES, M. B.; MACIEL, F. Alfabetização. Brasília: MEC / Inep / Comped, 2000.

TRALDI JR., Armando e PIRES, Célia M. C. Grupo colaborativo e o desenvolvimento profissional de formadores de professores de matemática. Zetetiké - Cempem /FE/ Unicamp, Campinas, v. 17, n. 31, p. 47-84, jan./jun. 2009.

SKOVSMOSE, O. Desafios da Educação Matemática Crítica. São Paulo: Papirus, 2008.

Submetido em julho de 2015

Aprovado em novembro de 2015 